\title{
Os permanentes fora de área: $O$ acesso e a Atenção à Saúde para população sem
}

\section{terra}

\author{
Permanents outside area: Access and Health Care for landless population
}

Residentes permanentes fuera del área: Acceso y Atención Médica para la población sin tierra

Recebido: 08/04/2021 | Revisado: 16/04/2021 | Aceito: 20/04/2021 | Publicado: 06/05/2021

\author{
Mariana de Figueiredo Silva \\ ORCID: https://orcid.org/0000-0002-2704-8616 \\ Universidade Federal do Rio Grande do Norte, Brasil \\ E-mail: mariana.silva1897@gmail.com \\ Laianny Krizia Maia Pereira \\ ORCID: https://orcid.org/0000-0002-2407-9943 \\ Universidade Federal do Rio Grande do Norte, Brasil \\ E-mail: laiannykmp@hotmail.com \\ Dannielly Azevedo de Oliveira \\ ORCID: https://orcid.org/0000-0003-0108-3912 \\ Universidade Federal do Rio Grande do Norte, Brasil \\ E-mail: danniellyazevedo3@gmail.com \\ José Adailton da Silva \\ ORCID: https://orcid.org/0000-0002-6037-7649 \\ Universidade Federal do Rio Grande do Norte, Brasil \\ E-mail: joseadailtonmec@icloud.com
}

\begin{abstract}
Resumo
Objetivou-se identificar a percepção da população Sem Terra sobre o acesso aos serviços de saúde e a atenção à saúde. Trata-se de um estudo exploratório-descritivo, de natureza qualitativa. A coleta de dados consistiu em entrevista semiestruturada individual com 11 sujeitos, entre acampados e assentados do Movimento dos Trabalhadores Rurais Sem Terra (MST) situados no estado do Rio Grande do Norte, no Nordeste brasileiro. O tratamento dos dados ocorreu através da técnica de análise de conteúdo na qual houve a delimitação de duas categorias: A vida no MST e a Atenção à saúde. O cotidiano retrata condições de moradia e de trabalho precárias, agricultura familiar e expectativa de melhorias com a posse da terra. Existe dificuldade de acesso, as ações de saúde são restritas e pontuais, voltadas para o modelo hegemônico. Destaca-se a importância de melhorar o acesso aos serviços, com gestão participativa, planejando ações intersetoriais atrelada às demais políticas do Ministério da Saúde (MS) com o intuito de promoção à saúde.
\end{abstract}

Palavras-chave: Assentamentos humanos; População vulnerável; Acesso aos serviços de saúde; Atenção à saúde.

\begin{abstract}
The objective was to identify the perception of the landless population about access to health services and health care. This is a descriptive exploratory study, of a qualitative nature. The data collection consisted of an individual semistructured interview with 11 subjects, between campers and settlers from the Movement of Landless Rural Workers (MST) located in the state of Rio Grande do Norte, in the Brazilian Northeast. The treatment of the data occurred through the technique of content analysis in which there was the delimitation of two categories: Life in the MST and Health Care. The daily life portrays precarious housing and work conditions, family farming and expectations of improvements with land tenure. There is difficulty in access, health actions are restricted and punctual, focused on the hegemonic model. It highlights the importance of improving access to services, with participatory management, planning intersectoral actions linked to the other policies of the Ministry of Health (MS) in order to promote health. Keywords: Human settlements; Populations Vulnerable; Health services accessibility; Health care.
\end{abstract}

\section{Resumen}

El objetivo fue identificar la percepción de la población sin tierra sobre el acceso a los servicios de salud y la atención de la salud. Se trata de un estudio exploratorio descriptivo, de carácter cualitativo. La recolección de datos consistió en una entrevista individual semiestructurada con 11 sujetos, entre campistas y pobladores del Movimiento de Trabajadores Rurales Sin Tierra (MST) ubicado en el estado de Rio Grande do Norte, en el Nordeste brasileño. El tratamiento de los datos se dio a través de la técnica de análisis de contenido en la que se delimitó dos categorías: Vida en el MST y Atención a la Salud. La vida cotidiana retrata condiciones precarias de vivienda y trabajo, agricultura familiar y expectativas de mejora con la tenencia de la tierra. Hay dificultad de acceso, las acciones de 
salud son restringidas y puntuales, enfocadas en el modelo hegemónico. Destaca la importancia de mejorar el acceso a los servicios, con gestión participativa, planificando acciones intersectoriales vinculadas a las demás políticas del Ministerio de Salud (MS) con el fin de promover la salud.

Palabras clave: Asentamientos humanos; Población vulnerable; Accesibilidad a los servicios de salud; Atención a la salud.

\section{Introdução}

O Movimento dos Trabalhadores Rurais Sem Terra (MST) surgiu em 1984 mediante um encontro de trabalhadores rurais e diversas entidades e organizações populares e sindicais em Cascavel, no Paraná, onde estes buscavam entender os problemas dos sem-terra e como enfrentá-los (Morissawa, 2001). Com isso, foram elencados os objetivos do movimento que seriam: lutar pela terra, lutar pela reforma agrária e por uma sociedade justa e fraterna (Barros \& Teixeira, 2018).

A luta do movimento para uma reforma agrária almejou não somente a redistribuição da propriedade e do uso da terra, mas também garantir a produção agropecuária com um desenvolvimento agrícola autossustentável, promover a geração de emprego e buscar um desenvolvimento rural através de investimentos em educação, cultura, saúde e habitação no interior, promovendo cidadania e justiça social para todos (Morissawa, 2001).

Essas populações estão incluídas na Política Nacional de Saúde Integral das Populações do Campo e da Floresta (PNSIPCF), que foi instituída em 2011, sendo definida por ser uma política transversal com gestão e execução compartilhadas entre as três esferas de governo. Tem como objetivo promover a saúde das populações do campo e da floresta, através de atividades e iniciativas que compreendam as especificidades de gênero, raça, etnia e orientação sexual, visando ao acesso aos serviços de saúde, a diminuição de riscos e agravos à saúde provenientes das atividades desempenhadas para fins agrícolas, além de melhorar os indicadores de saúde e a qualidade de vida (Brasil, 2013).

Dessa forma, a PNSIPCF também busca contribuir para a redução das vulnerabilidades em saúde das populações; promover planejamentos participativos capazes de identificar as demandas de saúde das populações e definir metas, estratégias e ações específicas com articulações intersetoriais para promover a saúde (Brasil, 2013).

$\mathrm{Na}$ prática, muitas famílias permanecem, por alguns períodos, em lugares próximos às rodovias, sem condições de moradia adequadas e susceptíveis a diversos problemas de saúde que requer uma Rede de Atenção à Saúde (RAS) adequada às necessidades dessa parcela da população.

A RAS é definida como organizações poliárquicas composta por diversos serviços de saúde que estão intimamente interligados prestando uma atenção contínua e integral de qualidade a população nos três níveis de atenção à saúde, abrangendo ações de promoção, prevenção, cura, cuidado, reabilitação e paliativas. E ainda assume responsabilidade sanitária e econômica sobre a população adscrita no território (Mendes, 2011).

No contexto de saúde pública tem-se a Atenção Primária à Saúde (APS) como porta de entrada do usuário para o Sistema Único de Saúde (SUS) em que esta atende às necessidades, principalmente dos problemas mais comuns da comunidade. Além disso, conhece o contexto social ao qual a população está adscrita no território, o que facilita a resolução do problema. Sendo fundamental para determinar o trabalho a ser desempenhado pelos demais níveis de atenção, quando for o caso (Starfield, 2002).

A Política Nacional de Atenção Básica (PNAB) tem na Estratégia de Saúde da Família (ESF) a ferramenta mais eficaz para promover a expansão e consolidação da Atenção Básica, propiciando garantia de saúde à população, qualidade do atendimento ofertado e a sua alta resolutividade. Busca articular ações intersetoriais, assim como a organização da RAS, com ênfase nas necessidades locorregionais (Brasil, 2017).

Imagina-se que as pessoas Sem Terra dependem exclusivamente da rede hospitalar e não possuem acesso aos serviços de atenção básica, por não terem relação direta com vínculo e território definido, o que é uma problemática no contexto da 
saúde pública. Deste modo, o presente estudo irá discorrer acerca da percepção da população Sem Terra sobre o acesso aos serviços de saúde e a atenção à saúde.

Com isso questiona-se: qual a percepção da população Sem Terra acerca das condições de saúde, do acesso aos serviços de saúde e da atenção à saúde? A população do MST sente-se contemplada pelos programas e estratégias já existentes? Quais as expectativas de ações de saúde destas pessoas? Existem ações de atenção básica voltadas para este público?

Destaca-se que, embora exista a PNSIPCF, foi visto que seus objetivos ainda não contempla as necessidades de saúde da população (Brasil, 2013). Pois, o primordial que é o acesso aos serviços de saúde ainda se encontra fragilizado, principalmente para a população que se encontra acampada, seja pelo deslocamento até o serviço ou mesmo ter uma Unidade Básica de Saúde (UBS) de referência que possa oferecer uma atenção à saúde e ordenar o cuidado nos demais níveis de atenção da rede, com o intuito de amenizar as dificuldades enfrentadas pela população para ter assistência à saúde.

Nesse contexto, esse estudo traz importantes contribuições para a discussão do acesso aos serviços de saúde e atenção integral para a população do campo, incluindo o MST. As singularidades dos "permanentes fora de área", ao serem destacadas tendem a ampliar a visibilidade da problemática nesse cenário. Assim, conhecer a realidade das condições de vida e saúde desta população constitui-se em importante passo com vista a alavancar o planejamento de políticas públicas e pesquisas que contemplem esse público, contribuindo para produção de ações de saúde pública para esse público prioritário.

A motivação em realizar essa pesquisa surgiu da curiosidade de como os Sem Terra sobreviviam a margem da rodovia e como acontecia o acesso e a atenção à saúde para eles, visto que moravam a margem da rodovia distante dos serviços de saúde. Essa vivência se deu através do percurso feito para a faculdade, em que observava os barracos e muitas indagações surgiam, querendo encontrar respostas para a situação que eles estavam submetidos.

Nesse sentido, este estudo teve por objetivo identificar a percepção da população Sem Terra sobre o acesso aos serviços de saúde e a atenção à saúde. E, mais especificamente, verificar quais as expectativas sobre condições de vida e ações de saúde são esperadas por estas pessoas; conhecer quais serviços de saúde estão disponíveis para a população dos MST na percepção dos próprios sujeitos; e, identificar a existência de ações de atenção básica e outros serviços de saúde utilizados pela população do MST.

\section{Metodologia}

O presente estudo é do tipo exploratório-descritivo e de natureza qualitativa.

A pesquisa qualitativa é justificada, uma vez que se preocupa em investigar e interpretar aspectos mais profundos, descrevendo a complexidade do comportamento humano, fornecendo análises mais detalhadas sobre as investigações, hábitos, atitudes e tendência de comportamento dos sujeitos envolvidos (Lakatos \& Marconi, 2017). Além de descrever fenômenos como a percepção dos sujeitos, suas condições de vida e acesso aos serviços de saúde.

Foi desenvolvida no local de moradia dos sujeitos que correspondem aos acampados do acampamento Retomada Trairi, em que o início do MST surgiu há menos de um ano, sendo localizado no município de Tangará que pertence a V Região de Saúde com polo na cidade de Santa Cruz. Os assentados do assentamento Irmã Dorothy que já existe há 14 anos e está localizado no município de Ceará-Mirim que engloba a III Região de Saúde, com sede em João Câmara. Ambos os locais do MST estão situados no estado do Rio Grande do Norte, no Nordeste Brasileiro, totalizando aproximadamente 40 e 12 famílias, respectivamente (universo da pesquisa). A intenção de entrevistar grupos com diferença no tempo de surgimento dos grupos foi averiguar se isso influenciava o modo de organização da população. 
Foi adotado como critério de inclusão que os participantes não possuíssem nenhum tipo de distúrbio cognitivo grave que impossibilitasse a comunicação ou lucidez; aceitar participar da pesquisa assinando o Termo de Consentimento Livre e Esclarecido - TCLE e, como critério de exclusão a idade ser inferior a 18 anos.

Para tanto, estabeleceu-se contato inicial com o líder, por meio telefônico, no qual foi apresentado a pesquisa e este compartilhou com os demais.

A coleta de dados consistiu em uma entrevista semiestruturada com duração média de 20 minutos por entrevistado, com gravação de áudio, com prévia autorização dos participantes. Além disso, foi garantida a privacidade dos sujeitos com a presença apenas do entrevistador. O roteiro contemplou: a coleta de informações socioeconômicas e queixas de saúde, e a análise das experiências, necessidades e expectativas dos sujeitos sobre o acesso aos serviços de saúde. Este foi previamente testado com o intuito de avaliar o instrumento de coleta, necessitando de alterações para melhor entendimento e outros aspectos relacionados aos objetivos da pesquisa.

Para atingir os objetivos propostos pelo estudo, houve delimitação dos sujeitos arrolados de modo que foram selecionados de forma intencional no dia de coleta, desde que estivessem no local do MST e por manifestação voluntária dos participantes, sendo entrevistados 11 sujeitos, sem nenhuma desistência, em três momentos que possibilitou alcançar os objetivos do estudo, após verificar-se a saturação das falas.

A entrevista é uma conversa direcionada a uma pessoa de maneira sistemática (Lakatos \& Marconi, 2017), possibilitando uma visão ampla da realidade que se quer investigar. Esta etapa foi realizada por dois dos pesquisadores, sendo uma enfermeira generalista e um professor universitário e, este doutor em saúde coletiva, com expertise no método. A entrevista utilizando roteiro semiestruturado possibilitou aos entrevistados discorrer sobre o tema em questão sem se prender à indagação formulada (Minayo, 2014).

Apesar de existir um roteiro para nortear as entrevistas, esta técnica se caracteriza, também, por deixar os sujeitos livres para expressarem suas opiniões, críticas e sugestões, o que ocasiona uma interação mais dinâmica, necessária para expressar a visão dos envolvidos na pesquisa.

Depois, as falas foram transcritas que conforme Meihy (2002) passam pela etapa de transcrição, processo de mudança do estágio oral para o código escrito.

No tratamento dos dados obtidos a partir das entrevistas, foi utilizada a técnica de análise do conteúdo que delimitou duas categorias: A vida no MST e a Atenção à saúde, por meio da pré-análise, exploração do material, tratamento dos resultados, inferência e interpretação (Bardin, 2016).

A pré-análise compreendeu a leitura das entrevistas, após a transcrição destas. Em seguida, a exploração do material, que consistiu na organização dos dados em planilha de texto, a partir da compreensão do sentido das falas para constituir as categorias temáticas. No tratamento dos resultados, inferência e interpretação que caracterizam a terceira fase foi realizada uma análise comparativa das informações, ressaltando os aspectos comuns e os divergentes para concretizar as proposições da pesquisa (Bardin, 2016).

A análise do material coletado consistiu na interpretação dos dados colhidos articulado ao conhecimento apreendido com a leitura crítica do referencial bibliográfico trabalhado, no qual possibilitou a comparação com teorias já existentes e a formulação de novas proposições.

O estudo foi realizado em consonância com as exigências da Resolução 466/2012 do Conselho Nacional de Saúde, com aprovação do projeto pelo Comitê de Ética em Pesquisa da Faculdade de Ciências da Saúde do Trairi, sob o parecer de $n^{\circ}$ 3.015.151. Para manter o sigilo dos sujeitos participantes do estudo, estes foram identificados com o pseudônimo de instrumentos de trabalho relacionadas ao campo. 


\section{Resultados e Discussão}

Participaram do estudo 11 pessoas, identificadas por pseudônimos de instrumentos de trabalho relacionadas ao campo. Foram 73\% (8) do sexo feminino e 27\% (3) do sexo masculino, com idades entre 25 e 65 anos. A escolaridade dos participantes corresponde a $82 \%$ (9) que possuem ensino fundamental incompleto, 9\% (1) que concluiu o ensino médio e $9 \%$ (1) que concluiu o ensino superior.

No tocante a renda familiar, esta variou de $\mathrm{R} \$ 89,00$ a 5.800,00. Quanto ao recebimento de benefício de algum programa social, $73 \%$ (8) eram beneficiários.

Dos entrevistados, 64\% (7) possuem estado civil solteiro, 18\% (2) em união estável e 18\% (2) viúvos.

A seguir, no Quadro 1, apresenta a caracterização dos sujeitos participantes da pesquisa.

Quadro 1 - Caracterização dos sujeitos da pesquisa.

\begin{tabular}{|c|c|l|l|l|l|}
\hline Pseudônimo & $\begin{array}{c}\text { Tempo } \\
\text { no MST }\end{array}$ & Idade & Sexo & Estado civil & Escolaridade \\
\hline Arado & 8 meses & 58 anos & feminino & solteira & Ensino Fundamental Incompleto \\
\hline Bota de borracha & 5 meses & 65 anos & feminino & solteira & Ensino Fundamental Incompleto \\
\hline Carroça & 2 meses & 39 anos & feminino & união estável & Ensino Fundamental Incompleto \\
\hline Enxada & 2 meses & 59 anos & masculino & viúvo & Ensino Fundamental Incompleto \\
\hline Faca & 4 meses & 37 anos & feminino & solteira & Ensino Médio completo \\
\hline Foice & 8 meses & 54 anos & feminino & viúva & Ensino Fundamental Incompleto \\
\hline Martelo & 8 meses & 47 anos & masculino & solteiro & Ensino Fundamental Incompleto \\
\hline Pulverizador & 4 meses & 47 anos & feminino & união estável & \\
\hline Roçadeira & 5 anos & 57 anos & masculino & solteiro & Analfabeta \\
\hline Semente & 1 dia & 32 anos & feminino & solteira & Ensino Fundamental Incompleto \\
\hline Serrote & 4 meses & 25 anos & feminino & solteira & Ensino Fundamental Incompleto \\
\hline
\end{tabular}

Fonte: Autores (2019).

Os resultados foram organizados em duas categorias: a vida no MST e a atenção à saúde, conforme objetivos do estudo.

\subsection{A vida no MST}

A vida no MST expressa o cotidiano das famílias nos assentamentos e acampamentos, com suas lutas diárias e o objetivo de conquistar uma estabilidade com a posse da terra.

Os acampamentos podem ser vistos como cidades de barracos de lona, em razão do material utilizado e ao tipo de habitação, sendo bem comum estarem situados à margem de rodovias. E nomeia-se assentamento, quando a terra que estava sendo pleiteada já foi conquistada, dando início a organização de uma nova comunidade que possibilita melhores condições de vida (Caldart, 2004). 
Os acampados esperam por melhores condições de vida (habitação, saneamento básico, alimentação, educação, trabalho, transporte) com a conquista da terra como afirma Barros e Teixeira (2018), no qual as famílias assentadas quando comparadas às acampadas, possuem melhores condições de vida e de saúde, o que demonstra a importância da garantia do direito à terra para a população do campo.

E isso é retratado na fala de Enxada, em que a terra é percebida como algo que vai garantir melhor qualidade de vida para que ele possa aproveitar os anos que ainda tem para viver, com mais comodidade. Além disso, atua na construção de uma identidade coletiva e da reconstrução da subjetividade individual (Caume, 2002).

\section{"Eu quero receber a terra para trabalhar e findar o resto [da vida] que já estou numa idade dessa e não tem mais para onde ir. Para os mais jovens o emprego está difícil, imagina para os mais velhos" (Enxada)}

Com a posse da terra será possível garantir ao assentado o desenvolvimento da agricultura familiar, não sendo mais necessário ter que plantar em terras alheias, nas quais eles têm que pagar de alguma forma pelo cultivo da terra, nesse caso é com parte da produção como menciona Foice em sua fala.

"Se plantarmos dez mil covas e colher 100 quilos, 70 é do dono da terra e 30 é nosso. E a gente tendo nossa terra não vamos pagar a ninguém" (Foice)

Porém, enquanto não se tem a propriedade da terra é necessário encontrar uma maneira de suprir as necessidades de sobrevivência e consumo dos camponeses, sendo o trabalhar para o outro o meio encontrado, já que não existem incentivos políticos e econômicos para sua produção agrícola (Santos \& Hennington, 2013).

A falta de estabilidade financeira faz com que algumas famílias dependam da doação de mantimentos para garantir o alimento de cada dia e isso também foi encontrado no estudo de Figueiredo e Pinto (2014), em que foi relatado que quando a doação alimentícia não era suficiente algumas pessoas chegaram a passar fome.

"Quando ele pega biscaide [algum trabalho] ele coloca dentro de casa, quando eu não saio pedindo mesmo doente para não passar necessidade [fome]" (Pulverizador)

A agricultura desenvolvida no acampamento é destinada apenas para complementar o sustento familiar porque devido a extensão de terra ser pequena, se torna inviável o cultivo de mais alimentos, como fica evidente na fala de Roçadeira.

"Tem-se trabalhado o quintal produtivo [espaço de 20 metros do centro da rodovia para dentro da fazenda que se destina ao DNIT (Departamento Nacional de Infraestrutura de Transportes ou DER (Departamento de Estradas e Rodagens)] que ajuda no sustento com o cultivo de hortaliças, macaxeira, batata e feijão" (Roçadeira)

A vida no MST, devido as condições insalubres de moradia e trabalho, interfere no processo saúde-doença da comunidade, como demonstra o estudo de Ricardo e Stotz (2012), onde os fatores do adoecimento estão associados a uma alimentação precária, a vida sob lona preta, a falta de saneamento básico e a ausência de luz elétrica sendo, portanto, algumas das dificuldades enfrentadas pela população que vive acampada. 
"Aqui é quente demais, minha pressão sobe, os rins dói todo dia" (Pulverizador) "Eu internei ele sábado [o neto dela] que ele tem cansaço, aí aqui é muito quente e ele cansou" (Foice)

O clima da região caracteriza-se pela temperatura elevada e o material que faz a cobertura dos barracos é de lona, favorecendo ainda mais para o aquecimento e causando consequências para a saúde dos moradores, conforme foi dito anteriormente por Pulverizador e Foice.

Além desse fator, o comprometimento da saúde também teve relação com a jornada de trabalho excessiva que implica no tempo de descanso, inclusive para fazer as refeições nas horas certas.

"Eu tive anemia, estou em tratamento. Que eu passava o dia no acampamento as vezes só comia uma vez por dia" (Foice)

O presente estudo apresenta divergência com Figueiredo e Pinto (2014) que apontam a falta de alimento como fator limitante e não a falta de descanso para se alimentar; e com Santos e Hennington (2013) que abordam um tempo de descanso reduzido e a jornada de trabalho assalariado como fatores que afetam a saúde, pois a mudança nesses padrões acarreta em uma menor produtividade e repreensão por parte dos patrões.

Para o assentado que está há cinco anos no movimento e exerce função de líder do MST, o comprometimento da saúde tem relação, principalmente, com a ocorrência de acidentes.

"A maioria [dos problemas de saúde] são acidentes porque nós já somos acostumados com água quente, poeira, sol" (Roçadeira)

Dentre os principais agravos à saúde desse tipo de população estão a excessiva exposição à radiação solar, esgotamento físico e os acidentes, seja com equipamentos cortantes ou com animais peçonhentos, demonstrando convergência com os dados encontrados nesse estudo (Barros \& Teixeira, 2018).

Desse modo, é importante que os profissionais de saúde conheçam o contexto social em que o indivíduo está inserido, assim como sua concepção acerca do processo saúde-doença para propor mudanças no que for necessário, promovendo o bemestar com ações de promoção da saúde.

Tendo em vista isso, o grupo do MST desse estudo tem um sistema de cota para arrecadar dinheiro todo mês dos acampados, em que quatro por cento desse valor é para ser revertido em alimentação ou medicamentos quando situações como estas ocorrem, pois acabam impactando no modo de sobrevivência de uma família, já que a maioria desempenha atividades autônomas.

A vida no MST é marcada pela falta de opção e oportunidade de outra forma de vida, mostrando a ausência do Estado nas ações afirmativas, uma vez que muitos Sem Terra decidem entrar em um acampamento devido a necessidade ou por possuir uma visão ainda ingênua de mundo. E, é com a vivência no acampamento que essas pessoas vão construindo o significado de luta pela terra, a partir dos processos educativos do movimento social, enraizando-se em uma coletividade (Caldart, 2004).

O líder do movimento afirmou que em governos anteriores o Instituto Nacional de Colonização e Reforma Agrária (INCRA) distribuía cestas básicas para os assentamentos/acampamentos, porém no momento não existe mais incentivo financeiro para arcar. 
No Art. $6^{\circ}$ da Constituição Federal a moradia é um direito social, assim como a saúde e alimentação (Constituição, 1988). Porém, o que se pode comprovar é que esses direitos não estão sendo garantidos, já que as pessoas buscam encontrar no movimento social uma maneira de conseguir um terreno, construir uma casa e manter-se com o que foi produzido, a fim de garantir a sobrevivência.

"Se eu tivesse um canto [casa para morar], se eu tivesse condições eu já tinha alugado um canto para eu morar, mas eu não tenho"(Pulverizador)

" O lugar não é muito bom, não é adequado, mas dá para sobreviver. Só em não ter que pagar aluguel [economizar esse dinheiro] porque as condições financeiras não dão para se manter" [alimentação]. (Carroça)

"A única solução que tenho é ficar aqui, não é bom, não é fácil tá o dia a dia levando sol, chuva, é muito ruim, mas fazer o quê"(Carroça)

O presente estudo corrobora com o estudo de Figueiredo e Pinto (2014), uma vez que no acampamento são vivenciadas dificuldades que colocam em risco a própria existência física do acampado - fome, fragilidade dos barracos e exposição a intempéries.

A vida no MST é norteada pela resistência e luta para o bom uso da terra, em que embora enfrentam condições insalubres de moradia estão lá dia a dia engajados no trabalho, com expectativa de melhorias. Além disso, observa-se o empenho dos acampados em plantar mesmo que seja no pequeno terreno disponível, entre o barraco e a rodovia, a fim de contribuir para o sustento familiar e mostrar que realmente eles estão ali porque necessitam de uma terra e que querem torná-la produtiva.

"A força do acampamento, a força do movimento é cada dia mais juntando forças com a massa [população] e com isso a gente ter voz, porque a gente não tem voz se não tiver massa (Roçadeira)"

"Com a conquista da terra vai fazer [ser desenvolvido] a agricultura, criação de animais"(Faca)

A conquista da propriedade da terra e a organização da agricultura é identificada como o fato de devolver a vida, regado por uma transformação da própria vida social, através do desenvolvimento do processo produtivo da terra em coletividade (Fontoura Júnior, Souza, Renovato \& Sales, 2012).

"Eu espero que se eu ganhar ao menos um pedaço de terra pra colocar meus filhos debaixo [construir uma casa] pra mim já era suficiente"(Carroça)

"Eu trabalho, mas não é em terra minha. É na beira da BR que plantamos, que eu não tenho terra"(Bota de borracha)

O depoimento de Carroça e Bota de borracha vem mais uma vez reafirmar a necessidade do direito à terra como fator benéfico para a vida das pessoas Sem Terra, tendo em vista que a casa propicia mais segurança e conforto e a terra é considerada como um meio de sobrevivência, pois garante a produção de alimentos. 


\subsection{Atenção à saúde}

Esta categoria expressa as intervenções em saúde realizadas nos acampamentos/assentamentos, bem como a ausência destas nos espaços do território.

A existência de ações de Atenção Básica utilizadas no grupo pesquisado é restrita e pontual, não havendo uma atenção integral com foco no território voltado para as especificidades locorregionais, abrangendo um cuidado longitudinal que busca garantir qualidade de vida com ações de promoção da saúde, a fim de reduzir vulnerabilidades e fatores de risco, relacionados aos seus determinantes e condicionantes (Brasil, 2018).

"Toda sexta-feira de 15 em 15 dias vem o médico, a enfermeira e uma ajudante. Tem uma casa que aceita eles para nos atender"(Foice)

Os assentados procuram o serviço de saúde, buscando ações assistenciais ou preventivas, porém existe a dificuldade de acesso para chegar ao local, como também para ser atendido, pois muitos afirmaram ter que pernoitar nas filas para obter atendimento, além da má qualidade ao serem assistidos. Os assentados relatam reivindicarem às Secretarias Municipal e Estadual de Saúde um local no assentamento para receber os profissionais de saúde ao menos uma vez por mês, porém não obtiveram êxito (Santos \& Hennington, 2013).

Já os sujeitos do presente estudo frisaram que quando precisavam se consultar o atendimento era prestado. Isso, se na UBS mais próxima fosse dia de expediente, pois a unidade não funcionava todos os dias. Entretanto, o cuidado não é continuado devido a dificuldade para o deslocamento, procurando quando é estritamente necessário. Relataram ainda que antes um ACS realizava visitas domiciliares, no entanto não há mais.

"Precisa ficar nos visitando, nós também somos gente, vim olhar as crianças"(Serrote)

"Tinha um agente de saúde que fazia acompanhamento das crianças, marcava ficha para atendimento quando a criança estava doente porque é longe, mas agora ele saiu"(Foice)

É preciso que uma equipe de saúde esteja vinculada ao acampamento para que as pessoas tenham acesso aos serviços de saúde oferecidos à população, e as ações programáticas da atenção básica sejam garantidas, como consultas de saúde da criança para avaliar o crescimento e o desenvolvimento destas.

"O sítio é esquecido, só é mais lembrado pra rua"(Enxada)

"Essas pessoas elas já vêm [de algum bairro], neste local tem o cadastro no posto de saúde (Roçadeira)"

"Tivemos uma visita no acampamento para verificar pressão, corte de cabelo, aplicação de flúor nos dentes das crianças"(Roçadeira)

A fala de Roçadeira corresponde a uma ação social que aconteceu no assentamento Irmã Dorothy, onde existe uma UBS próximo que atende a população e nessa atividade a equipe realizou algumas ações de promoção da saúde.

A assistência à saúde é baseada no modelo hospitalocêntrico em que os indivíduos procuram o serviço de saúde em busca da cura sem compreender que a saúde não é somente ausência de afecções e enfermidades, mas também depende de 
fatores políticos, econômicos, sociais, culturais, ambientais e comportamentais que impactam no processo saúde-doençacuidado (Buss, Hartz, Pinto \& Rocha, 2020). Dessa forma, o lugar onde as pessoas moram impacta na qualidade de vida delas, por isso a importância de ter uma equipe de ESF vinculada ao território. Então, o processo de saúde-doença será mais bem compreendido e as ações serão voltadas para o foco do problema e não apenas no sintoma que o usuário apresentou.

"Se for uma dor a gente dá o remédio, espera mais ou menos um dia, se viu que não resolveu vai pro hospital e resolve"(Faca)

"Eu vou para o hospital mesmo, não tem posto de saúde não, eu procuro o hospital que quando minha pressão sobe fica 20,20/8 [...] aí fica dando uma agonia no coração"(Pulverizador)

"A gente procura a urgência no hospital" (Enxada)

Com isso, pode-se constatar que a população do MST ainda está inserida numa atenção à saúde voltada para o modelo hegemônico, focado na doença, na cura, dissociado do contexto social. Embora devesse prevalecer a lógica da ESF que é o modelo assistencial substitutivo, no qual prioriza a promoção da saúde e a prevenção das enfermidades, com ênfase na família e na comunidade em detrimento apenas da clínica do paciente, pois esse novo modelo da atenção primária à saúde propicia melhores condições de saúde da população (Esmeraldo, Oliveira Esmeraldo Filho \& Queiróz, 2017).

Os permanentes fora de área, assim que acampam em algum local não possuem unidade de referência, seja UBS ou hospital, demandando algum tempo até regularizar os documentos, de modo que a rede não está preparada para esta parcela da população, pois geralmente as equipes já se encontram com uma quantidade de pessoas que extrapolam o limite adequado, interferindo em uma atenção à saúde de qualidade.

"Tem os agentes de saúde que sempre passam nas casas, aí acompanham nós também". Inclusive estava faltando meu peso no cadastro, ela [a agente de saúde] foi e ligou para mim"(Faca)

A fala de Faca vem no contexto de que algumas pessoas possuem o cadastro em UBS de locais que já moraram, então eles mantêm o endereço de alguém conhecido para ter assistência à saúde quando precisam. Embora isso seja uma prática comum não deveria ocorrer, porque assim a atenção básica se torna semelhante ao atendimento hospitalar, voltado apenas para tratar problemas agudos, sem compreender o contexto social em que o indivíduo está inserido e desenvolver ações que impactem positivamente na realidade de saúde da população.

"É o hospital regional e o PSF lá da rua"(Carroça)

"Não, só o posto de saúde e a maternidade, somente"(Arado)

"Vou pro hospital, lá eles me atendem, o médico me atende. Só não passa remédio pra pressão porque tem que ser o médico da área, mas se a pessoa tá com dor chega lá eles dão injeção"(Bota de borracha)

Durante a pesquisa ficou notório que a população apenas procura o serviço de saúde para se consultar, não sendo participativo nas demais ações desenvolvidas pela ESF como prevenção, promoção e reabilitação. Assim, como cita Barros e 
Teixeira (2018) o acesso aos serviços de saúde acontece somente quando os sintomas de alguma doença se agravam, e isso tem relação com a dificuldade em chegar a UBS, fazendo com que o usuário não previna o aparecimento de doenças ou cuidando, enquanto o seu início é precoce e há possibilidade de cura.

\section{Considerações Finais}

A pesquisa revelou que é necessário melhorar o acesso da população Sem Terra aos serviços de saúde, pois embora exista a PNSIPCF esta não foi implementada como deveria, requerendo ainda a elaboração de instrumentos com orientações específicas, bem como articulação intersetorial para fortalecer o planejamento das ações a serem desenvolvidas. A política é transversal, dependendo da articulação às demais políticas do MS e empenho da gestão para garantir o acesso e a atenção integral à população do MST.

As condições de vida dos indivíduos são precárias, o que interfere na saúde deles. A população Sem Terra tem sua expectativa de vida como reflexo das situações vivenciadas por eles. Com relação às melhorias na qualidade de vida, a perspectiva aumenta quando estes conseguem a posse da terra para desfrutar de um local mais extenso para desenvolver a agricultura e, assim, garantir meios de sobrevivência com uma moradia digna, alimentação, educação, saneamento básico e trabalho.

Existem serviços disponíveis que atendem os Sem Terra. Uma UBS e o atendimento hospitalar de urgência em um município, porém a dificuldade de acesso é a mesma para ambos, principalmente, pelo deslocamento devido à distância.

O que pode ser constatado é que a Atenção Básica oferece um cuidado pontual a essa população, apenas nas sextasfeiras a cada 15 dias. E como nunca houve visita dos profissionais no acampamento, o que se pode considerar é que estes desconhecem os problemas do território, ou seja, a atenção à saúde é voltada somente para clínica do usuário, sem perspectivas de mudanças na realidade local da população através da promoção da saúde.

Dessa forma, ressalta-se a importância de a gestão intervir nesse local, garantindo que profissionais prestem a devida atenção à saúde, extremamente necessária em acampamentos, já que a saúde é direito garantido por lei à toda e qualquer população. Todavia torna-se importante desenvolver ações de integração ensino-serviço-comunidade com o intuito da promoção à saúde, bem como, mais pesquisas na área para permear a visibilidade de como vive a população Sem Terra e desencadear maior qualidade de vida com o acesso e a atenção à saúde aos serviços.

\section{Referências}

Bardin, L. (2016). Análise de conteúdo. Edições 70.

Barros, L. D.V., \& Teixeira, C. F. (2018). Movimento dos Trabalhadores Rurais Sem Terra e saúde do campo: revisão integrativa do estado da arte. Saúde debate, 2 (42), 394-406. 10.1590/0103-11042018S227

Brasil. (2013). Política Nacional de Saúde Integral das Populações do Campo e da Floresta. Brasília: Editora do Ministério da Saúde. http://bvsms.saude.gov.br/bvs/publicacoes/politica_nacional_saude_populacoes_campo.pdf

Brasil. (2017). Portaria No 2.436, de 21 de setembro de 2017. Aprova a Política Nacional de Atenção Básica, estabelecendo a revisão de diretrizes para a organização da Atenção Básica, no âmbito do Sistema Único de Saúde (SUS). Ministério da Saúde. http://bvsms.saude.gov.br/bvs/saudelegis/gm/2017/prt2436_22_09_2017.html

Brasil. (2018). Política Nacional de Promoção da Saúde. Anexo I da Portaria de Consolidação nº 2 , de 28 de setembro de 2017 . Ministério da Saúde. http://bvsms.saude.gov.br/bvs/publicacoes/politica_nacional_promocao_saude.pdf

Buss, P. M., Hartz, Z. M. A., Pinto, L. F., \& Rocha, C. M. F. (2020). Promoção da saúde e qualidade de vida: uma perspectiva histórica ao longo dos últimos 40 anos (1980-2020). Rev. Ciência \& Saúde Coletiva, 25 (12), 4723-4735. 10.1590/1413-812320202512.15902020.

Caldart, R. S. (2004). Pedagogia do Movimento Sem Terra. Expressão Popular.

Caume, D. J. (2002). A tessitura do "assentamento de reforma agrária": discursos e práticas instituintes de um espaço agenciado pelo poder. Tese de doutorado, Universidade Estadual de Campinas, Campinas, SP, Brasil. 
Research, Society and Development, v. 10, n. 5, e25810514803, 2021

(CC BY 4.0) | ISSN 2525-3409 | DOI: http://dx.doi.org/10.33448/rsd-v10i5.14803

Constituição da República Federativa do Brasil de 1988. (1988). http://www.planalto.gov.br/ccivil_03/constituicao/constituicaocompilado.htm.

Esmeraldo, G. R. O. V., Oliveira, L. C., Esmeraldo Filho, C. E., \& Queiroz, D. M. (2017). Tensão entre modelo biomédico e Estratégia Saúde da Família: Percepções dos trabalhadores de saúde. Rev. APS, 20 (1), 98-106. https://doi.org/10.34019/1809-8363.2017.v20.15786

Figueiredo, G. C., \& Pinto, J. M. R. (2014). Acampamento e assentamento: participação, experiência e vivência em dois momentos da luta pela terra. Psicologia \& Sociedade, 26 (3), 562-571. http://www.scielo.br/pdf/psoc/v26n3/a05v26n3.pdf

Fontoura Júnior, E. E., Souza, K. R., Renovato, R. D., \& Sales, C. M. (2011). Relações de saúde e trabalho em assentamento rural do MST na região de fronteira Brasil- rab. Educ. Saúde, 9 (3), 379-397. 10.1590/S1981-77462011000300003.

Lakatos, E. M., \& Marconi, M. A. (2017). Fundamentos de metodologia científica. (5a ed.). Atlas.

Meihy, J. C. S. B. (2002). Manual de História Oral. (4a ed.). Loyola.

Mendes, E. V. (2011). As Redes de Atenção à Saúde. (2a ed.). Brasília: Organização Pan-Americana da Saúde. http://bvsms.saude.gov.br/bvs/publicacoes/redes_de_atencao_saude.pdf

Minayo, M. C. S. (2014). O desafio do conhecimento: pesquisa qualitativa em saúde. (14a ed.). Hucitec.

Morissawa, M. (2001). A história da luta pela terra e o MST. Expressão Popular.

Ricardo, L. M., \& Stotz, E. N. (2012). Educação Popular como Método de Análise: Relações entre Medicina Popular e a "situação-limite” vivenciada por trabalhadores do Movimento dos Trabalhadores Rurais $\quad$ Sem-terra. Rev APS, $15 \quad$ 435-442. <http://www6.ensp.fiocruz.br/repositorio/sites/default/files/arquivos/Educa\%C3\%A7\%C3\%A3oPopular.pdf>

Santos, J. C. B., \& Hennington, E. A. (2013). Aqui ninguém domina ninguém: sentidos do trabalho e produção de saúde para trabalhadores de assentamento do Movimento dos Trabalhadores Rurais Sem Terra. Cad. Saúde pública, 29 (8), 1595-1604. 10.1590/0102-311X00096612.

Starfield, B. (2002). Atenção primária: equilíbrio entre necessidades de saúde, serviços e tecnologia. UNESCO. ttps://www.nescon.medicina.ufmg.br/biblioteca/imagem/0253.pdf 